\title{
Re-emergence of leishmaniasis in Spain: community outbreak in Madrid, Spain, 2009 to 2012
}

A Arce (araceli.arce@salud.madrid.org) ${ }^{1}$, A Estirado ${ }^{1}$, M Ordobas ${ }^{1}$, S Sevilla ${ }^{1}$, N García ${ }^{1}$, L Moratilla ${ }^{1}$, S de la Fuente ${ }^{2}$, A M Martínez2, A M Pérez ${ }^{1}$, E Aránguez ${ }^{2}$, A Iriso ${ }^{2}$, O Sevillano $^{2}$, J Bernal ${ }^{2}$, F Vilas $^{2}$

1. Division of Epidemiology, Health Promotion and Prevention Subdirectorate, Primary Care Directorate, Madrid, Spain

2. Division of Health Environmental, Ordination and Inspection Directorate, Health Department, Madrid, Spain

Citation style for this article:

Arce A, Estirado A, Ordobas M, Sevilla S, García N, Moratilla L, de la Fuente S, Martínez AM, Pérez AM, Aránguez E, Iriso A, Sevillano O, Bernal J, Vilas F. Reemergence of leishmaniasis in Spain: community outbreak in Madrid, Spain, 2009 to 2012. Euro Surveill. 2013;18(30):pii=20546. Available online: http://www. eurosurveillance.org/ViewArticle.aspx?Articleld $=\mathbf{2 0 5 4 6}$

Article submitted on 24 August 2012 / published on 25 July 2013

Since July 2009, there has been a community outbreak of leishmaniasis in the south-west area of the Madrid autonomous community, Spain, affecting residents from four towns that are geographically close together and share extensive park areas. As of December 2012, 446 cases were reported (6 in 2009, 97 in 2010, 196 in 2011 and 147 in 2012), a mean incidence rate of 22.2 per 100,000 inhabitants during July 2009 and December 2012. The mean age was 44 years (range: 2 months to 95 years); $61.0 \%$ were male. A total of $68(15.2 \%)$ had immunosuppressive conditions; 160 (35.9\%) had visceral leishmaniasis and $286(64.1 \%)$ cutaneous. A total of 421 (94.4\%) cases were confirmed. Leishmania infantum was identified as the agent. Monitoring revealed high densities of the vector Phlebotomus perniciosus. The surveillance system for canine leishmaniasis did not detect any increase in prevalence during the period. Environmental control measures have been taken, such as improvements in sanitation and disinsection in the risk areas and control of the overpopulation of Leporidae, as xenodiagnosis studies have shown that hares play a role as active reservoirs. This is the largest reported community outbreak of leishmaniasis in Europe. The discovery of the new reservoir stands out in the multifactorial aetiology of the outbreak. Epidemiological research and environmental intervention measures are continuing.

\section{Introduction}

Human leishmaniasis is a zoonotic disease endemic in the Mediterranean basin, including Spain [1-4]. In Spain, the vector involved in the transmission of the parasite (genus Leishmania) is a sandfly of the Phlebotomus genus (primarily $P$. perniciosus), which is active between May and October and dogs are the main reservoir [3-5].

There is a formal system for reporting all compulsorily notifiable diseases, with notification protocols including case definitions. The notification process starts from physicians, primary care and hospitals, or from microbiology laboratories, which report to the Spanish and Madrid Epidemiological Surveillance Network. All cases are reviewed by an epidemiologist. In the Madrid autonomous community, leishmaniasis has been monitored through the notifiable diseases surveillance system since 1997, although state-level reporting of this disease is not compulsory [6]. The Spanish Public Health Department's approach to the disease calls for coordinated research and control actions, both epidemiological and environmental. The services in charge of environmental research are developing surveillance programmes for vectors and canine leishmaniasis in the community's animal protection centres [7].

During 2000 to 2009, between 12 and 25 leishmaniasis cases have been reported per year in the region (with an annual incidence rate of around 0.5 per 100,000 inhabitants) [6]. During the last quarter of 2010, a fivefold increase was detected in the number of cases compared with the number seen in the whole year of previous years. Subsequent research confirmed that an outbreak of leishmaniasis had been occurring since July 2009 in the south-west area of the region of Madrid [8].

The aim of this article is to describe the epidemiological characteristics of the urban community outbreak of leishmaniasis and the control measures adopted.

\section{Methods}

After detecting an unusual increase in the number of leishmaniasis cases in Madrid, the Epidemiological Surveillance Network intensified surveillance using different strategies. Coordination was strengthened through periodic meetings with the professionals involved, in both primary and secondary health care, and active case finding was conducted. A retrospective search for cases was performed using information from microbiology laboratories and hospital discharge records. Epidemiological research was intensified using a questionnaire administered by telephone, to gather information on patients' place of residence, their work environment and leisure activities. Patients 
were asked about the presence of dogs, sick dogs, mosquitoes (oriented on the habitat an characteristics of the sandflies), waste and rubbish dumps, and livestock farms in these environments during last year. Questions were also asked about their travel history during the incubation period to areas that were highly endemic for the disease.

A specific case definition was established for the outbreak: a case was a person who met the clinical and laboratory criteria for leishmaniasis defined by the Epidemiological Surveillance Network, with residence in the towns located on the south-west area of the region of Madrid and with onset date of symptoms between 1 July 2009 and 31 December 2012. People affected lived in four towns - defined as the epidemic area - located geographically close together (Fuenlabrada, Leganés, Getafe and Humanes de Madrid), which share large urban parks and have a population over half a million inhabitants. It was considered that 1 July 2009 was the onset date of the outbreak because from that date, a steady increase in the number of cases was detected in the epidemic area; in the first six months of 2009, no cases were reported in this area. The Epidemiological Surveillance Network uses the case definition of leishmaniasis in the Notification system manual of notifiable diseases [9]. A probable case is a person that meets the clinical criteria of the case definition and may also have a positive serology (one-time positivity or titre increase of IgG). According to the manual, confirmatory diagnosis is made through demonstration of the presence of the parasite (visualisation, polymerase chain reaction (PCR) in aspirated samples or biopsy material obtained from the edges of a skin lesion (cutaneous leishmaniasis) or in a case of visceral leishmaniasis, from bone marrow, liver, spleen, lymph nodes or blood, or by the isolation of the parasite [9]. Laboratory analyses were carried out in the reference hospitals attended by each case and most cases were confirmed in the National Reference Laboratory for Leishmaniasis in Madrid (Instituto de Salud Carlos III, WHO Collaborating Centre for Leishmaniasis), where the pathogen was also classified.

We carried out a descriptive analysis of the epidemiological variables studied: sex, age, country of origin, onset date of symptoms, clinical presentation, classification of cases, diagnostic tests, intrinsic risk factors (immunosuppressive disease and/or immunosuppressive treatment), extrinsic risk factors (environmental exposure to the common vector and/or reservoir) and reporting delay. We analysed all the cases, separated according to their clinical presentation. The cases were georeferenced using the patients' place of residence.

Incidence rates for the period were calculated per town as the number of cases per 100,000 inhabitants. The population given in the continuous census for 2009

\section{FIGURE 1}

Outbreak cases of leishmaniasis by month of symptom onset and clinical presentation, region of Madrid, Spain, July 2009December $2012(n=446)$

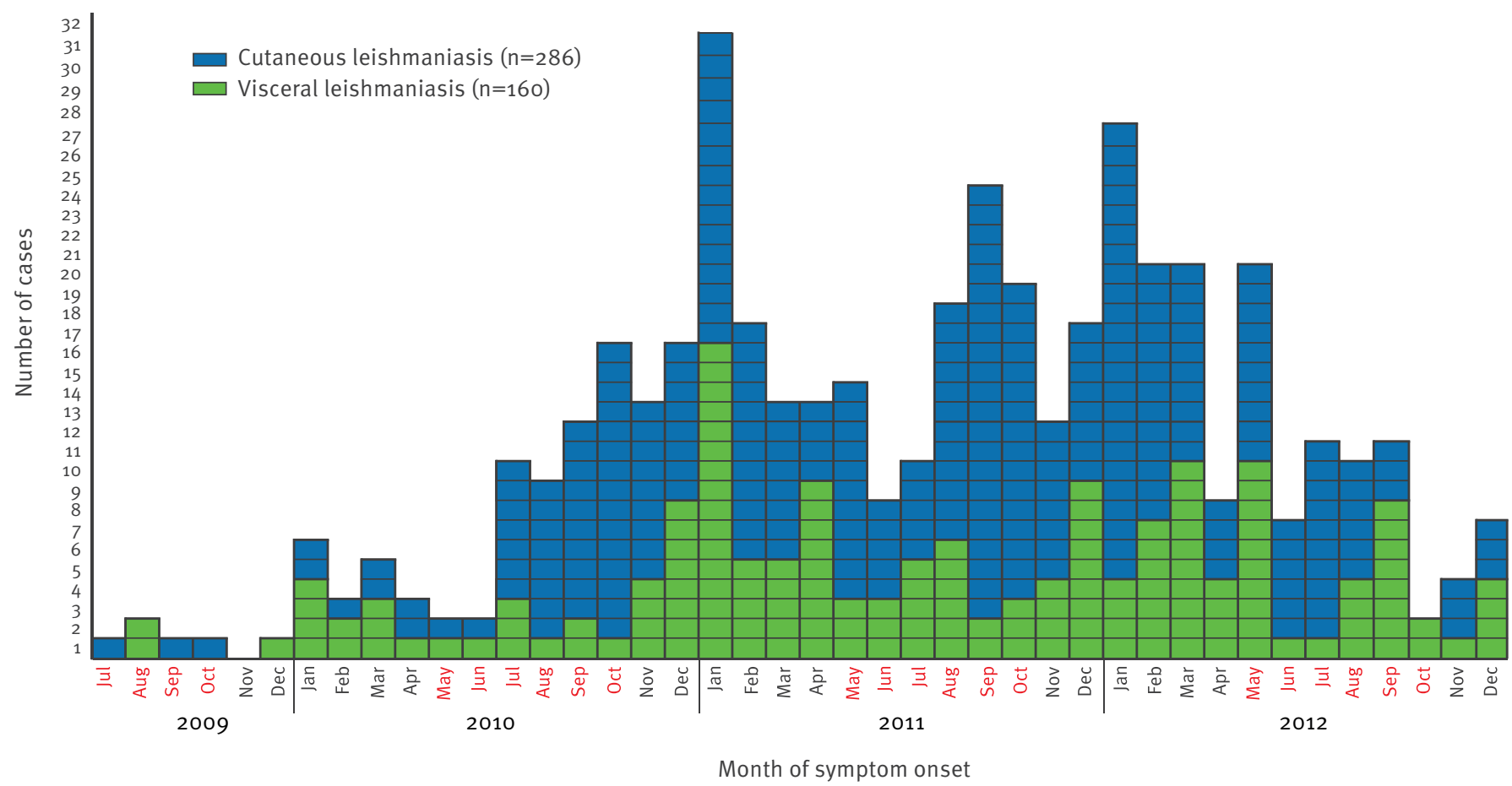

The months in which the vector is active (May to October) are shown in red. 
Spatial distribution of cases by place of residence and clinical presentation, community outbreak of leishmaniasis in the region of Madrid, Spain, July 2009-December $2012(n=446)$

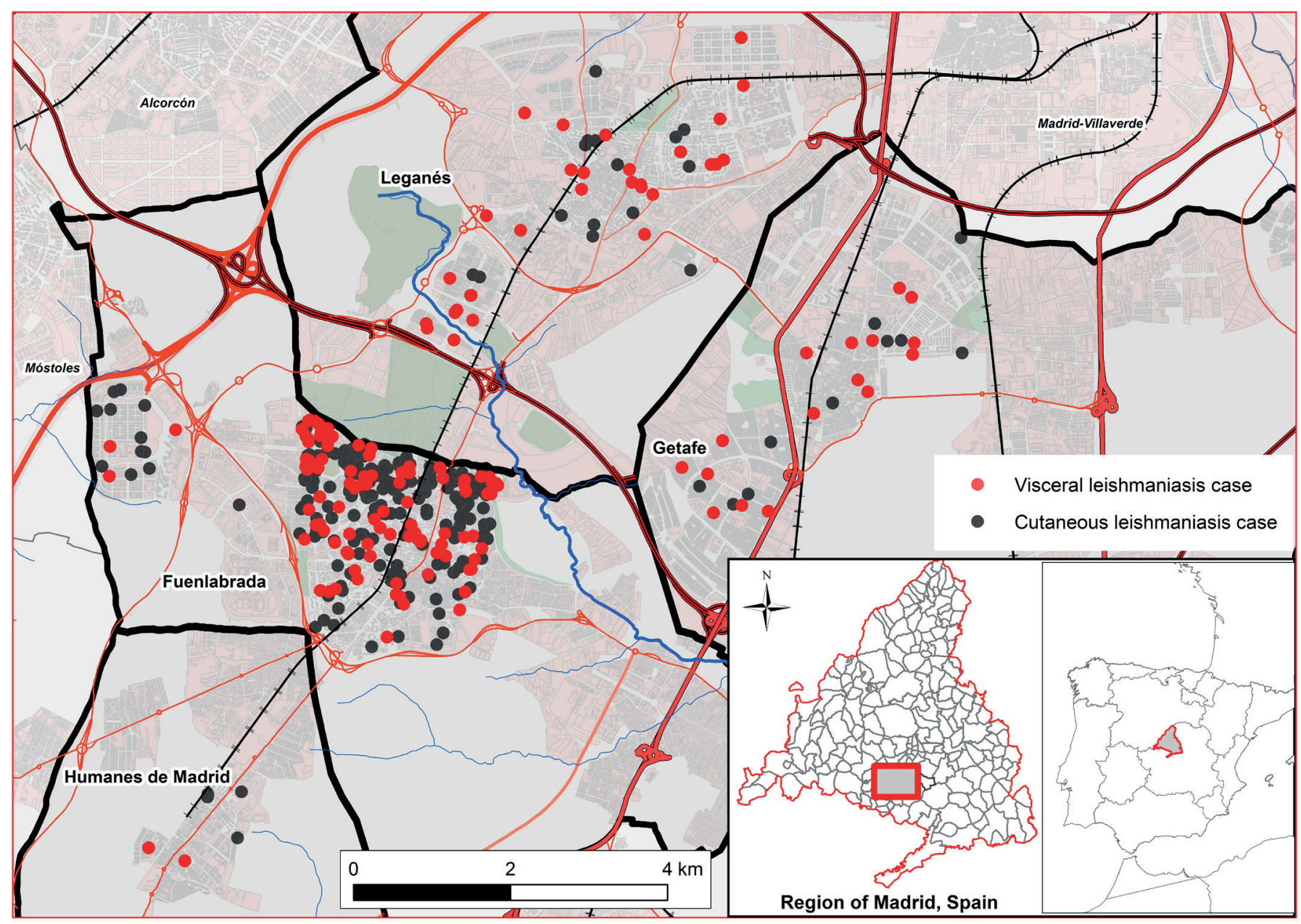

to 2012 published by the Institute of Statistics of the Community of Madrid [10] was used as denominator.

In environmental research, regional actions included in the canine leishmaniasis programme were adopted and specific measures were intensified in the outbreak area (monitoring of known and potential reservoirs and control measures). A sandfly surveillance system was implemented in the Madrid region in 2008 [7], involving 10 stations in various towns from May to October each year. Surveillance activities were intensified in the epidemic area, following the start of the outbreak.

\section{Results}

\section{Epidemiological investigation}

From 1 July 2009 to 31 December 2012, 542 cases of leishmaniasis were reported in the region of Madrid to the Epidemiological Surveillance Network, of which $446(82.3 \%)$ met the outbreak case definition: 6 were identified in 2009, 97 in 2010, 196 cases in 2011 and 147 cases in 2012. The mean incidence rate in the epidemic area was 22.2 cases per 100,000 inhabitants during the period under investigation. The outbreak is under control but new cases (fewer) are being reported.

The patients lived in the following towns in the region of Madrid: Fuenlabrada (366 cases; 52.7 per 100,000 inhabitants), Leganés ( 48 cases; 7.3 per 100,000 inhabitants), Getafe ( 26 cases; 4.4 per 100,000 inhabitants) and Humanes de Madrid (6 cases; 9.2 per 100,000 inhabitants). During 2000 to 2009, between 1 and 6 cases per year were detected in these four towns, with an incidence rate below 1.0 per 100,000 inhabitants.

The clinical presentation of patients in the outbreak was $35.9 \%$ visceral leishmaniasis (160 cases; 8.0 per 100,000 inhabitants). Of these, 140 had classical disease and 20 atypical presentations (18 localised lymphadenopathic leishmaniasis and two with mucosal leishmaniasis). The remaining $64.1 \%$ had cutaneous leishmaniasis (286 cases: 14.2 per 100,000 inhabitants). The epidemic curve by date of symptom onset and clinical presentation (Figure 1) and spatial distribution 


\section{FIGURE 3}

Distribution by sex, age group and clinical presentation, community outbreak of leishmaniasis in the region of Madrid, Spain, July 2009-December $2012(\mathrm{n}=446)$

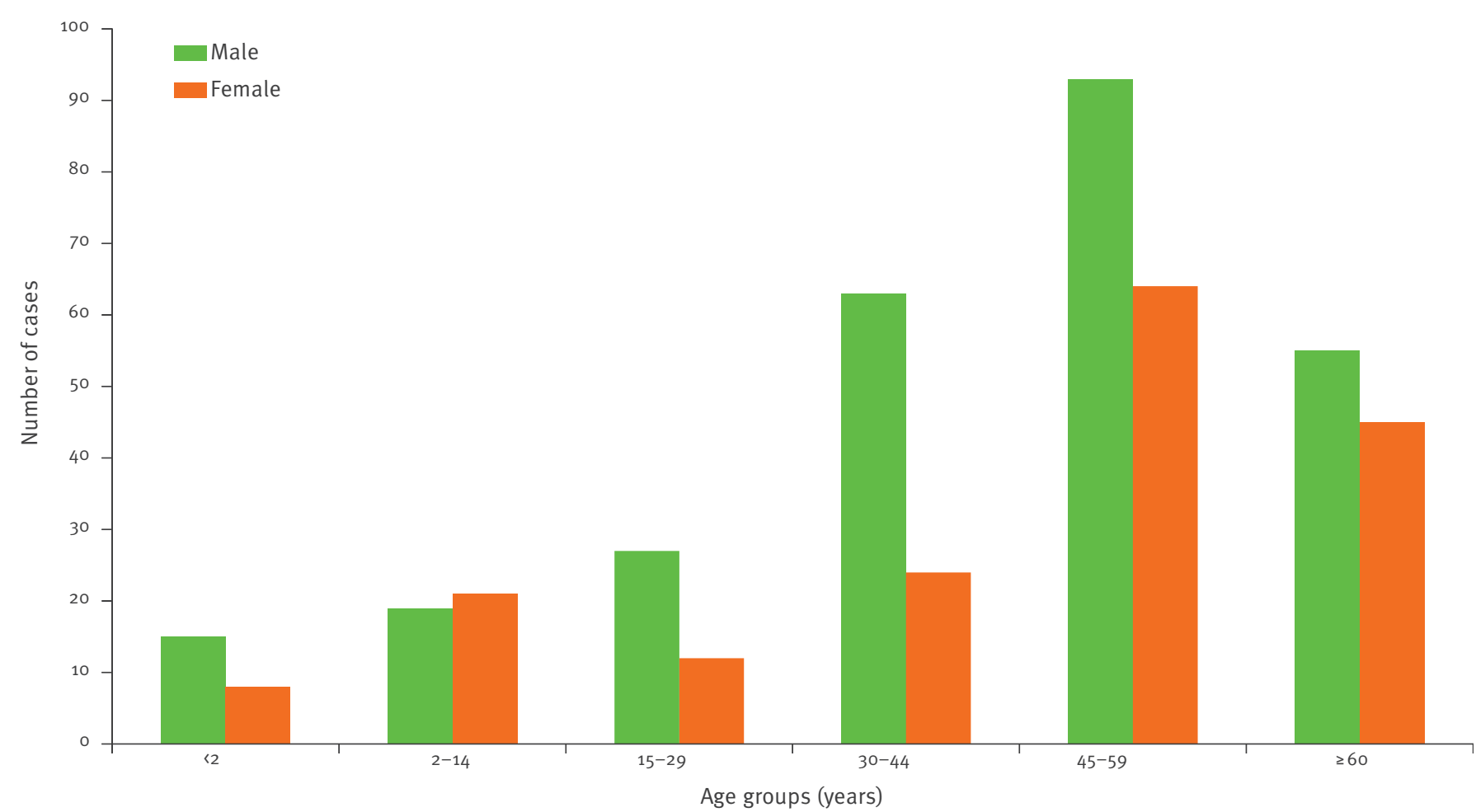

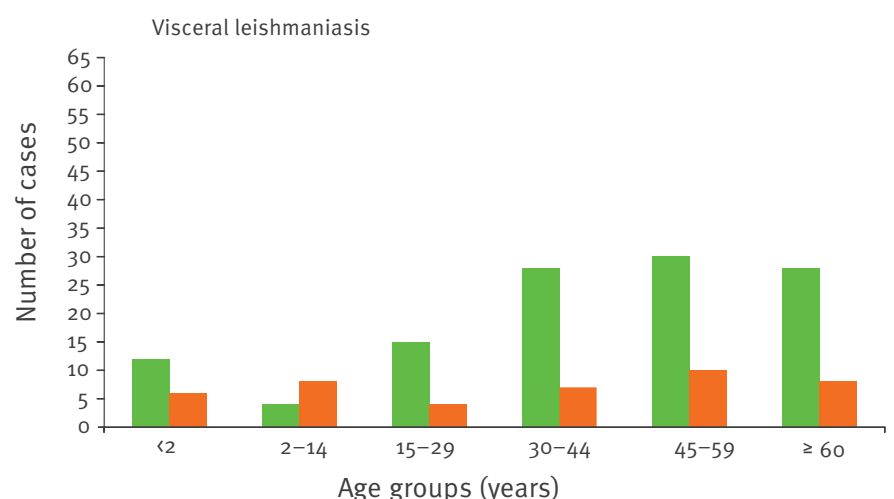

of cases by place of residence and clinical presentation (Figure 2) are shown.

The median reporting delay was 151 days ( 41 days for visceral leishmaniasis, with a minimum of 9 days and 183 days for cutaneous leishmaniasis, with a minimum of 35 days).

The distribution of cases by sex, age group and clinical presentation is shown in Figure 3. A total of 272 $(61.0 \%)$ of cases were male. The mean age of all cases was 44 years ( 40 years for the visceral leishmaniasis cases and 46 years for the cutaneous cases), ranging from 2 months to 95 years. It is worth noting that 15

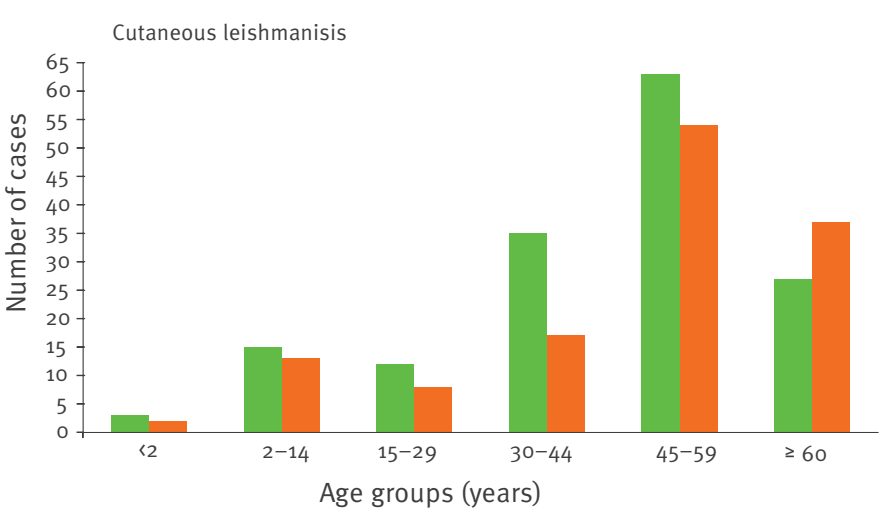

cases were infants under 1 year of age (11 with visceral leishmaniasis and 4 with cutaneous leishmaniasis) and 8 cases were aged between 12 and 23 months (7 with visceral leishmaniasis and 1 with cutaneous leishmaniasis).

The main clinical and epidemiological characteristics of the cases are shown in the Table. Some $68(15.2 \%)$ of cases were of foreign origin: of these, 44 had visceral forms and 24 cutaneous forms. A total of 36 patients (8.1\% of all cases) were born in sub-Saharan Africa (mostly from Equatorial Guinea and Nigeria), of which 32 had visceral leishmaniasis $(20.0 \%$ of all the visceral leishmaniasis cases). The number of cases who were 
TABLE

Clinical and epidemiological characteristics of leishmaniasis cases by clinical presentation, community outbreak in the region of Madrid, Spain, July 2009-December 2012 (n=446)

\begin{tabular}{|c|c|c|c|}
\hline \multirow{2}{*}{ Characteristic } & Visceral forms & Cutaneous forms & Total \\
\hline & Number of cases (\%)a & Number of cases (\%) & Number of cases (\%) \\
\hline Total & $160(35.9)$ & $286(64.1)$ & $446(100.0)$ \\
\hline \multicolumn{4}{|l|}{ Sex } \\
\hline Male & $117(73.1)$ & $155(54.2)$ & $272(61.0)$ \\
\hline Female & $43(26.9)$ & $131(45.8)$ & $174(39.0)$ \\
\hline$<2$ & $18(11.2)$ & $5(1.7)$ & $23(5.2)$ \\
\hline $2-14$ & $12(7.5)$ & $28(9.8)$ & $40(9.0)$ \\
\hline $15-29$ & $19(11.9)$ & $20(7.0)$ & $39(8.7)$ \\
\hline $30-44$ & $35(21.9)$ & $52(18.2)$ & $87(19 \cdot 5)$ \\
\hline $45-59$ & $40(25.0)$ & $117(40.9)$ & $157(35.2)$ \\
\hline$\geq 60$ & $36(22.5)$ & $64(22.4)$ & $100(22.4)$ \\
\hline Spain & $116(72.5)$ & $262(91.6)$ & $378(84.8)$ \\
\hline Sub-Saharan Africa & $32(20.0)$ & $4(1.4)$ & $36(8.1)$ \\
\hline Other countries & $12(7.5)$ & $20(7.0)$ & $32(7.2)$ \\
\hline \multicolumn{4}{|l|}{ Year the symptoms started } \\
\hline 2009 & $3(1.9)$ & $3(1.0)$ & $6(1.3)$ \\
\hline 2010 & $31(19.4)$ & $66(23.1)$ & $97(21.8)$ \\
\hline 2011 & $70(43.7)$ & $126(44.1)$ & $196(43.9)$ \\
\hline 2012 & $56(35.0)$ & $91(31.8)$ & $147(33.0)$ \\
\hline \multicolumn{4}{|l|}{ Classification } \\
\hline Confirmed & $137(85.6)$ & $284(99.3)$ & $421(94.4)$ \\
\hline Probable & $23(14 \cdot 4)$ & $2(0.7)$ & $25(5.6)$ \\
\hline \multicolumn{4}{|l|}{ Diagnosis method } \\
\hline Culture & $13(8.1)$ & $23(8.0)$ & $36(8.1)$ \\
\hline Serology & $100(62.5)$ & $0(0.0)$ & $100(22.4)$ \\
\hline \multicolumn{4}{|l|}{ Hospitalisation } \\
\hline Admitted to hospital & $135(84.4)$ & $1(0.3)$ & $136(30.5)$ \\
\hline \multicolumn{4}{|l|}{ Intrinsic risk factors } \\
\hline All & $50(31.3)$ & $18(6.3)$ & $68(15.2)$ \\
\hline Immunosuppressive treatment & $25(15.6)$ & $13(4 \cdot 5)$ & $38(8.5)$ \\
\hline HIV infection & $16(10.0)$ & $2(0.7)$ & $18(4.0)$ \\
\hline Other immunosuppressive conditions & $20(12.5)$ & $6(2.1)$ & $26(5.8)$ \\
\hline Alcoholism & $13(8.1)$ & $3(1.0)$ & $16(3.6)$ \\
\hline Drug injection & $1(0.6)$ & $1(0.3)$ & $2(0.4)$ \\
\hline \multicolumn{4}{|l|}{ Extrinsic risk factors ${ }^{b}$} \\
\hline Contact with dogs & $52(32.5)$ & $62(21.7)$ & $114(25.6)$ \\
\hline Contact with sick dogs & $7(4 \cdot 4)$ & $10(3.5)$ & $17(3.8)$ \\
\hline Presence of mosquitoes ${ }^{c}$ & $27(16.9)$ & $62(21.7)$ & $89(20.0)$ \\
\hline Waste and rubbish dumps & $6(3.8)$ & $10(3.5)$ & $16(3.6)$ \\
\hline Walks near livestock farms & $5(3.1)$ & $9(3.1)$ & $14(3.1)$ \\
\hline \multicolumn{4}{|l|}{ Travel history during the incubation period } \\
\hline Travel to highly endemic areas & $34(21.3)$ & $63(22.0)$ & $97(21.7)$ \\
\hline
\end{tabular}

HIV: human immunodeficiency virus.

a Apart from the totals, the percentages shown use the number of visceral leishmaniasis cases or number of cutaneous leishmaniasis cases as appropriate.

b In domestic or peridomestic zones in the last year.

Questions were oriented on the habitat and characteristics of sandflies. The word 'flebotomo' [sandfly] was not used, as it is not known by the general population. 
born in sub-Saharan Africa was high and it should be noted that in the outbreak area, people of sub-Saharan origin represented less than $1 \%$ of the total population.

Most cases $(n=421 ; 94.4 \%)$ were laboratory confirmed. L.infantum was identified as the causative agent. The remainder of the cases were probable.

Intrinsic risk factors that might decrease immunity were reported in $68(15.2 \%)$ cases: $50(31.3 \%)$ of cases of visceral leishmaniasis and $18(6.3 \%)$ in the cutaneous leishmaniasis cases, with more than one immunosuppressive conditions or treatment occurring in the same patient.

Among the environmental risk factors analysed, it is noteworthy that 114 (25.6\%) of cases had contact with dogs in one or more places in the domestic or peridomestic environment. A total of $56(12.6 \%)$ cases had a dog in the home as a pet and all the animals were correctly protected against sandfly bites. A total of 17 (3.8\%) cases reported having had contact with dogs that were apparently sick - without specifying the illness - which were subsequently checked to ensure that they were not affected by leishmaniasis.

\section{Environmental research and control measures} After the increase in the number of leishmaniasis cases was detected in 2010, many different environmental actions were initiated, aimed at researching and controlling the vector and reservoir.

\section{Monitoring of the vector}

A sampling plan was developed in the epidemic area with the positioning, monitoring and analysis of both sticky and light traps for sandflies from May to October each year. In 2011, 37 stations were monitored with sticky traps (222 sampling sites) and 10,161 sandflies were studied. In 2012, 24 sampling stations (120 sampling sites) were monitored with sticky traps and 23,160 sandflies were studied, detecting a predominance of $P$. perniciosus (66.1\%), the principal vector of Leishmania in the region. The mean density was very high, reaching 143.8 sandflies $/ \mathrm{m}^{2}$, with more than 17 sampling stations having levels above this figure (one was above 1,000 sandflies $/ \mathrm{m}^{2}$ ). Light traps were used in four stations, obtaining an average infection rate of $2.4 \%$ in the females collected.

The sandfly surveillance system implemented in the region of Madrid, which was intensified in the years following the start of the outbreak, showed an increase in the density of $P$. perniciosus in the epidemic area $(16$ sandflies $/ \mathrm{m}^{2}$ in 2008, 30 sandflies $/ \mathrm{m}^{2}$ in 2010 and 50 sandflies $/ \mathrm{m}^{2}$ in 2012) [11].

Monitoring of dogs, the main known reservoir In 2011 and 2012, we collected information from clinical veterinarians in the epidemic area. They reported that they had not recorded any increase in the leishmaniasis detection tests performed in their clinics, where the prevalence of canine leishmaniasis was around $5 \%$. In 2011, they performed leishmaniasis detection tests on 1,007 dogs during an anti-rabies vaccination campaign, using the rK39 blood test (BLK Fast Test, LETI), giving a prevalence of $1.0 \%$ in dogs that were household pets and $3.6 \%$ in dogs that were in dog pounds, results that were similar to those estimated in other studies performed in the region of Madrid [12,13]. Complementary analyses were also carried out on four serologically positive dogs: all four were positive by PCR for Leishmania and the species was analysed in 3 of them, identifying L. infantum.

Since 2012, these veterinarians have been piloting a sentinel system for notifying canine leishmaniasis cases. In 2012, representative sampling of 561 pet dogs during the anti-rabies vaccination campaign in the epidemic area revealed a Leishmania seroprevalence of $1.6 \%$. Similarly, a sample of 502 dogs in potentially risky areas, such as dog pounds, hunting dog packs and livestock units, showed a prevalence of $2.0 \%$.

Monitoring of other potential reservoirs, in

view of the results obtained in dogs

Other potential reservoirs are being investigated, such as hares, rabbits, cats and rats. Results obtained to date indicate that $30 \%$ of the hares studied in 2011 and 2012 were infected with the parasite and in xenodiagnosis tests, evidence of the transmission of $L$. infantum from hares to sandflies has been obtained [14].

Environmental control measures

Risk areas in the epidemic towns have been identified, in which environmental sanitation steps are being carried out (removal of vegetation debris, cleaning of wasteland, removal of rubble, as well as the issuing of recommendations to individuals and companies). Burrows are being destroyed in areas where this is feasible due to the land layout. A disinsection plan has been established in risk areas, in which periodical treatments with biological insecticides and pyrethroids are carried out (in 2012, there were four treatments: every two weeks in June, one in September and one in October). In some areas where higher sandfly densities were found, intensive treatment was carried out for seven days (in September), followed by treatment once a week until the end of vector activity in October.

The collection of abandoned animals was stepped up: 406 dogs and 381 cats were collected in 2011 and 880 dogs and cats in 2012.

A control plan for the population of hares and rabbits in the environment has been set up, with around 1,000 hares having been caught to date using nets, greyhounds and falcons, and legislation has been passed for some areas in the epidemic area to declare them as temporary emergency game zones [15].

In addition to reinforcing surveillance, more information has been given to professionals from veterinary centres, dog owners and the general public. The 
environmental actions have been carried out in coordination with the institutions involved (Departments of Health and the Environment, Town Councils in the area) and experts have given their advice (Instituto de Salud Carlos III Health Institute - WHO Collaborating Centre for Leishmaniasis, Veterinary Health Surveillance Centre, Veterinary Faculty and Biology Faculty of Complutense University in Madrid).

\section{Discussion}

Regular epidemiological surveillance allowed an outbreak of human leishmaniasis to be detected, which started in the second half of 2009. Up to December 2012, 446 cases were reported, representing over $80 \%$ of the cases reported in this period in the entire region of Madrid. To the best of our knowledge, this is the largest community outbreak described in Spain and in Europe. Furthermore, it occurred in an urban setting where the prevalence of leishmaniasis was previously very low, a very different case to other outbreaks described in the literature [16-22].

Under-reporting of cases becomes apparent when monitoring the disease $[1,2,23]$, which is more noticeable in the cutaneous form. In Madrid, over the past decade of monitoring this disease, $90 \%$ of the reported cases were visceral [6], whereas in the current outbreak, they represented $36 \%$ of the cases. Visceral leishmaniasis is a serious disease that requires a specific diagnosis and treatment, normally with hospital admission, a factor that favours the notification of the disease to the surveillance network. Cutaneous leishmaniasis is a less serious disease, which can heal spontaneously, and where an aetiological diagnosis is not reached if the disease is not suspected and specific tests are not requested, such as PCR of the skin sample. Such cases are therefore generally under-represented in surveillance data. In this outbreak, given that the healthcare system in the south-west area of Madrid had been alerted, a thorough diagnosis was probably requested in patients with signs of cutaneous leishmaniasis.

The median time between the date of symptom onset and reporting to the Public Health Service was 41 days for cases of visceral leishmaniasis, as opposed to 183 days for cutaneous leishmaniasis cases. The delay arises from a number of factors that may be related to the patient (delay in seeking care) or the healthcare system (delay in diagnosis and reporting). The delay was greater for cases with cutaneous leishmaniasis due to the fact that patients take longer to request care and doctors take longer to consider the differential diagnosis of leishmaniasis and must wait for confirmation in order to be able to report the case [23].

Cases were found in all age groups. In those with visceral leishmaniasis, more men have been affected in almost all the age groups - the sex difference being particularly obvious in those over 30 years of age. In the cutaneous forms, distribution according to sex was similar. The clinical manifestations were typical for the disease (although it was remarkable that $11 \%$ of cases with visceral leishmaniasis had localised lymphadenopathic leishmaniasis as the sole clinical presentation) and the evolution was favourable after receiving the recommended treatment $[2,4]$. It is notable that 15 cases were infants under 1 year of age and 8 cases were aged between 12 and 23 months. It is also worth mentioning that $8 \%$ of the patients originated from sub-Saharan Africa, a percentage that rose to $20 \%$ for the visceral leishmaniasis cases.

During 2009 to 2012, there were four periods of sandfly's active life cycle, with most leishmaniasis cases occurring in the winter of 2010/11. The incubation period for the disease is variable [2]; it ranged from one week to several months and was generally longer in cases of visceral leishmaniasis, which may explain why these cases appeared more frequently during the cold months of the year. The epidemic curve allowed us to generate a hypothesis that favourable conditions for the transmission of Leishmania in the reservoir and/ or vector began in the summer of 2009; it reached its peak in the summer of 2010 and continued in 2011. A gradual decrease in the number of cases was seen in 2012, following the introduction of control measures. Our hypothesis could be modified, depending on the evolution of the outbreak after 2012.

In most of the patients, there were no intrinsic risk factors that could alter their susceptibility to disease, although important differences were found according to the clinical form: $31 \%$ of visceral leishmaniasis cases and $6 \%$ of cutaneous leishmaniasis cases had intrinsic risk factors. In recent decades, leishmaniasis has been linked to decreased immunity and has been particularly associated with human immunodeficiency virus (HIV) infection [2-4,16]. In the outbreak described here, only $4 \%$ of all leishmaniasis cases were coinfected with HIV.

None of the cases had travelled during the incubation period to countries or areas that were highly endemic for the disease $[1,2]$ : therefore, the infection cannot be considered imported.

In Spain, dogs are considered to be the main reservoir for $L$. infantum [1-5,11-13]; in this outbreak, only $26 \%$ of cases acknowledged contact with dogs in their domestic or peridomestic environment and the cases with dogs as pets in their homes had already applied suitable methods to protect against sandfly bites [3,24]. In order to evaluate the possible presence of vectors, we asked patients about their environment (house, neighbourhood, work, leisure pursuits and holidays). In a low percentage of cases, there were rubbish dumps, presence of mosquitoes, etc. in their peridomestic zones. We also asked patients about the areas where they walked, but no areas could be identified through which most people had passed. Therefore, our epidemiological research did not identify any of the classic environmental risk factors $[2,3]$. 
During 2011, many environmental control measures were started, aimed at monitoring and controlling the reservoir and vector: these have been intensified and optimised during 2012. Given the role that dogs classically play as the reservoir, actions initially concentrated on their study, but the surveillance system did not detect any increase in the prevalence of leishmaniasis in these animals, with level being around 5\% [11-13].

Monitoring of the vector showed that $P$. perniciosus was present, a species that has been traditionally described in Spain and Madrid [25-27] and was found in high density in the epidemic area. An extension of the presence of this vector both in latitude and altitude has also been observed. Recent changes in the environment (large road-improvement works in some towns of the outbreak, warm autumns) [28,29] may have contributed to the high density.

As a high percentage of hares may be a source of infection for sandflies and may also be infected by them, these animals may be considered at least as secondary reservoirs for the infection. This would suggest the existence of a stable wild transmission cycle linked to the urban outskirts [14]. Although some of the urban parks in the areas around the four towns were recently created, there was traditionally a high rabbit and hare population in the land used for the parks. Town planning modifications over the past decade have probably modified the ecology of these Leporidae, moving from a woodland cycle to an urban one, encouraging their multiplication, as there are no predators such as birds of prey, wild boars, etc. This has also allowed their closeness to people, with whom they live alongside peacefully. The discovery of hares as reservoir has led to measures being taken aimed at controlling the hare and rabbit overpopulation [15].

Environmental aspects such as climate change, growing urbanisation, socio-economic development, etc. are causing changes in the epidemiology of infectious diseases $[2,23,30,31]$. Known environmental factors might have contributed to the genesis of this leishmaniasis outbreak, with the discovery of hares as secondary reservoirs being particularly significant. Epidemiological research and environmental intervention measures are continuing.
Acknowledgements

To all the healthcare staff who are taking part in the surveillance and control areas of the disease and patient care. To E. García-Puente for their special contribution regarding case notifications from Fuenlabrada hospital. To M. Pichiule (MIR) and to the Public Health Alerts Service for their contribution to the design and drafting of the extended epidemiological survey. To the veterinarians from the Public Health 9 Territorial Service (R. Artero, A. Basagoiti, M. Bentolila, M. Daza, J. Fernández, A. Ferrer, M. García, J.M. Obradors and A. San Martín) for their participation in control actions. Also to Public Health 10 Territorial Service (particularly D. Alves and L. Gutiérrez) and to the Environmental Health Service (particularly C. Escacena and J. Frutos). To the Parasitology Service from the National Microbiology Centre for its contribution and advice. To all the technicians and people in charge of the environmental control measures from the town councils and from the Department of the Environment. 


\section{References}

1. World Health Organization (WHO). Leishmaniasis: epidemiology and access to medicines. An update based on the outcomes of WHO regional meetings, literature review and experts' opinion. Geneva: WHO. Available from: http://www.who.int/leishmaniasis/resources/ leishmaniasis_epidemiology_access_to_medicine/en/

2. World Health Organization (WHO). Control of the leishmaniases: report of a meeting of the WHO Expert Committee on the Control of Leishmaniases, Geneva, 22-26 March 2010. Geneva: WHO; 2010. WHO technical report series; no. 949. Available from: http://whqlibdoc.who.int/trs/WHO TRS_949_eng.pdf

3. Ready PD. Leishmaniasis emergence in Europe. Euro Surveill. 2010;15(10): pii=19505. Available from: http://www. eurosurveillance.org/ViewArticle.aspx?Articleld=19505 PMid:20403308

4. Marty P, Pomares C, Michel G, Delaunay P, Ferrua B, Rosenthal E. [Mediterranean visceral leishmaniasis]. Bull Acad Natl Med. 2011;195(1):181-8. French. PMid:22039711

5. Gálvez R, Descalzo MA, Miró G, Jiménez MI, Martín O, Dos Santos-Brandao F, et al. Seasonal trends and spatial relations between environmental/meteorological factors and leishmaniosis sand fly vector abundances in Central Spain. Acta Trop. 2010;115(1-2):95-102. http://dx.doi.org/10.1016/j. actatropica.2010.02.009 PMid:20171154

6. Morbilidad por enfermedades de declaración Obligatoria. Comunidad de Madrid. A-0 2010. [Report: Morbidity compulsory notifiable diseases. Community of Madrid. Year 2010]. Boletín epidemiológico de la Comunidad de Madrid. 2011;17(11). Spanish. Available from: http://www.madrid.org/ cs/Satellite?blobcol=urldata\&blobheader=application $\% 2 F p d f \&$ blobheadername $1=$ Content-Disposition \&blobheadervalue $1=$ fil ename\%3DNoviembre2011.pdf\&blobkey=id\&blobtable=Mungo Blobs\&blobwhere $=1310910631705 \&$ ssbinary $=$ true

7. Iriso A, Gonzalez-Mora D, Magro S, Soto MJ, Outerelo R, Sevillano 0, et al. Surveillance of leishmaniasis in Madrid Region (Spain). International Conference of Emerging Vectorborne Diseases in a Changing European Environment. Montpellier, France. 10-12 May 2010. Available from: http:// international-conference2010.eden-fp6project.net/var/eden colloque/storage/fckeditor/file/Oral\%2opresentations_web. pdf

8. Brote comunitario de leishmaniasis en la zona suroeste de la Comunidad de Madrid. A-0 2011. [Report: Community outbreak of leishmaniasis in the southwest area of the Community of Madrid. Year 2011]. Boletín epidemiológico de la Comunidad de Madrid. 2011:17(12). Spanish. Available from: http://www. madrid.org/cs/Satellite?blobcol=urldata\&blobheader=applicat ion $\% 2$ Fpdf\&blobheadername1=Content-Disposition\&blobhead ervalue $1=$ filename $\% 3$ DDiciembre2011.pdf\&blobkey=id\&blobta ble $=$ MungoBlobs \&blobwhere $=1310962031549 \&$ ssbinary $=$ true

9. Manual de Notificación Sistema de Enfermedades de Declaración Obligatoria. Documentos Técnicos de Salud Pública no. 69. [Notification system manual of notifiable diseases. Public health technical papers, no. 69]. Madrid: Public Health Institute Community of Madrid; 2006. Available from: http://www.madrid.org/cs/Satellite?c $=C M$ Publicaciones FA\&cid $=1142284809709$ \&idConsejeria $=110926$ $6187266 \&$ idListConsj $=1109265444710 \&$ idOrganismo $=1142439$ 320383 \&language $=$ es\&pagename $=$ ComunidadMadrid $\% 2$ FEstr uctura \&sm=1109266101003

10. Poblaciones de referencia de la Comunidad de Madrid. Tablas. Instituto de Estadística de la Comunidad de Madrid. [Population statistics of the Community of Madrid. Basic demographic]. [Accessed 23 July 2013]. Available from: http:// www.madrid.org/iestadis/fijas/estructu/demograficas/ censos/ipob_ref_1.htm

11. Iriso A, Vázquez MA, Tello A, González D, Aranguez E, Soto MJ. Sistema de vigilancia de flebotomos (Diptera: Psychodidae) en la Comunidad de Madrid. [Surveillance System sandflies (Diptera: Psychodidae) in the Community of Madrid]. Rev. Salud ambient. 2013;13(Espec Congr):139. Spanish. Available from: http://ojs.easyapps.es/index.php/rsa/article/ download/465/386

12. Gálvez R, Miró G, Descalzo MA, Nieto J, Dado D, Martín O, et al. Emerging trends in the seroprevalence of canine leishmanisis in the Madrid region (central Spain). Vet Parasitol. 2010;169(34):327-34. http://dx.doi.org/10.1016/j.vetpar.2009.11.025 PMid:20031330

13. Miró G, Montoya A, Mateo M, Alonso A, García S, García A, et al. A leishmaniasis surveillance system among stray dogs in the region of Madrid: ten years of serodiagnosis (1996-2006). Parasitol Res. 2007;101(2):253-7. http://dx.doi.org/10.1007/ so0436-007-0497-8 PMid:17323100

14. Molina R, Jiménez MI, Cruz I, Iriso A, Martín-Martín I, Sevillano 0 , et al. The hare (Lepus granatensis) as potential sylvatic reservoir of Leishmania infantum in Spain. Vet Parasitol. 2012;190(1-2):268-71. http://dx.doi.org/10.1016/j. vetpar.2012.05.006 PMid:22677135

15. Resolución de 29 de marzo de 2012 de la Dirección General de Medio Ambiente, por la que se declara comarca de emergencia cinegética temporal los términos municipales de Alcorcón, Fuenlabrada, Getafe, Leganés y Móstoles (Boletin Oficial de la Comunidad de Madrid de 12 de abril de 2012). Spanish. Available from: http://www.madrid.org/wleg/servlet/Servido $r$ opcion $=$ VerHtml\&idnorma $=8765$ \& word $=S \&$ wordperfect $=N \&$ $\mathrm{pdf}=\mathrm{S}$

16. Gil-Prieto R, Walter S, Alvar J, de Miguel AG. Epidemiology of leishmaniasis in Spain based on hospitalizations records (1997-2008). Am J Trop Med Hyg. 2011;85(5):820-5. http:// dx.doi.org/10.4269/ajtmh.2011.11-0310 PMid:22049034 PMCid:PMC3205626

17. Campino L, Maia C. [Epidemiology of leishmaniasis in Portugal]. Acta Med Port. 2010;23(5):859-64. Portuguese. PMid:21144327

18. Diza E, Kansouzidou A, Gerou S, Vezyri E, Metallidis S, Antoniadis A. Leishmaniases in Northern Greece: seroprevalence of the infection and incidence of the disease during the period 2001-2006. Eur J Clin Microbiol Infect Dis. 2008;27(10):997-1003. http://dx.doi.org/10.1007/s10096-008-0538-y PMid:18512088

19. Vinitsky O, Ore L, Habiballa H, Cohen-Dar M. Geographic and epidemiologic analysis of the cutaneous Leishmaniasis outbreak in northern Israel, 2000-2003. Isr Med Assoc J. 2010;12(11):652-6. PMid:21243862

20. Alvar J, Bashaye S, Argaw D, Cruz I, Aparicio P, Kassa A, et al. Kala-azar outbreak in Libo Kemkem, Ethiopia: epidemiologic and parasitologic assessment. Am J Trop Med Hyg. 2007;77(2):275-82. PMid:17690399

21. Mestre GL, Fontes CJ. [The spread of the visceral leishmaniasis epidemic in the State of Mato Grosso, 1998-2005]. Rev Soc Bras Med Trop. 2007;49(1):42-8. Portuguese. http://dx.doi. org/10.1590/So037-86822007000100008

22. Werneck GL, Rodrigues L, Santos MV, Araújo IB, Moura LS, Lima SS, et al. The burden of Leishmania chagasi infection during an urban outbreak of visceral leishmaniasis in Brazil. Acta Trop. 2002;83(1):13-8. http://dx.doi.org/10.1016/ So001-706X(02)00058-X

23. Dujardin JC, Campino L, Ca-avate C, Dedet JP, Gradoni $\mathrm{L}$, Soteriadou K, et al. Spread of vector-borne diseases and neglect of Leishmaniasis, Europe. Emerg Infect Dis. 2008;14(7):1013-8. http://dx.doi.org/10.3201/eid1407.071589 PMid:18598618 PMCid:PMC2600355

24. Palatnik-de-Sousa CB, Day MJ. One Health: the global challenge of epidemic and endemic leishmaniasis. Parasit Vectors. 2011;4:197. http://dx.doi.org/10.1186/1756-3305-4-197 PMid:21985335 PMCid:PMC3214158

25. Barón SD, Morillas Márquez F, Morales-Yuste M, Díaz-Sáez V, Irigaray C, Martín-Sánchez J. Risk maps for the presence and absence of Phlebotomus perniciosus in an endemic area of leishmaniasis in southern Spain: implications for the control of the disease. Parasitology. 2011;138(10):1234-44. http://dx.doi. org/10.1017/So031182011000953 PMid:21854702

26. Gálvez, R, Descalzo, MA, Guerrero I, Miró G, Molina R. Mapping the current distribution and predicted spread of the leishmaniosis sand fly vector in the Madrid region (Spain) based on environmental variables and expected climate change. Vector Borne Zoonotic Dis. 2011;11(7):799-806. http:// dx.doi.org/10.1089/vbz.2010.0109 PMid:21417927

27. Aransay AM, Ready PD, Morillas-Marquez F. Population differentiation of Phlebotomus perniciosus in Spain following postglacial dispersal. Heredity (Edinb). 2003:90(4)316-25 http://dx.doi.org/10.1038/sj.hdy.6800246 PMid:12692585

28. Inaugurada la nueva $M-407$ entre Fuenlabrada y Leganés. [Inauguration of the new M-407 between Fuenlabrada and Leganés]. EL PAÍS. 24 Mar 2011. Spanish. [Accessed 23 July 2013]. Available from: http://elpais.com/elpais/2011/03/24/ actualidad/1300958250_850215.html

29. Bosque Sur. Wikipedia. [Accessed 23 July 2013]. Spanish. Available from: http://es.wikipedia.org/wiki/Bosque_Sur

30. Franco AO, Davies CR, Mylne A, Dedet JP, Gállego M, Ballart $C$, et al. Predicting the distribution of canine leishmaniasis in western Europe based on environmental variables. Parasitology. 2011;14:1-14.

31. Semenza JC, Menne B. Climate change and infections diseases in Europe. Lancet Infect Dis. 2009;9(6):365-75. http://dx.doi.org/10.1016/S1473-3099(09)70104-5 